\title{
New perspectives in neurosteroid action: open questions for future research
}

\author{
Rainer Rupprecht* \\ Department of Psychiatry and Psychotherapy, University of Regensburg, Regensburg, Germany \\ ${ }^{*}$ Correspondence: rainer.rupprecht@medbo.de
}

Edited by:

Valerio Magnaghi, Università Degli Studi di Milano, Italy

Reviewed by:

Alessandro Faroni, The University of Manchester, UK

Giulia Puja, Università degli Studi di Modena e Reggio Emilia, Italy

Keywords: neurosteroid, allopregnanolone, TSPO, GABA, ion channel

Neurosteroids are still a hot topic in cellular and systemic neuroscience although the first report on anaesthetic actions of progesterone from Selye was published already in 1941 (Selye, 1941). It is a fascinating concept that endogenous metabolites of progesterone such as allopregnanolone and pregnanolone are powerful allosteric modulators of $\gamma$-aminobutyric acid type $\mathrm{A}\left(\mathrm{GABA}_{\mathrm{A}}\right)$ receptors. This at a first glance simple principle created by nature raises several questions that still are major challenges for neurosteroid research. What is the exact site of interaction of such neurosteroids with $\mathrm{GABA}_{\mathrm{A}}$ receptors? Is it really a binding site with clear saturable binding kinetics or rather an interaction site? Recent studies show that photolabeling of amino acids in the third transmembrane domain of the $\beta 3$ subunit of the $\mathrm{GABA}_{\mathrm{A}}$ receptor by neurosteroid analogs is feasible (Chen et al., 2012) but does this really prove a binding site? What makes the difference in the regulation of GABAergic neurotransmission between the modulation by a $3 \alpha$-reduced neurosteroid such as allopregnanolone and a benzodiazepine? Both are positive allosteric modulators of $\mathrm{GABA}_{\mathrm{A}}$ receptors and enhance GABAergic neurotransmission but there appear to be great differences with regard to abuse liability and tolerance development (Rupprecht et al., 2009). Do they merely target different subunit compositions? An argument against this hypothesis is that allopregnanolone does not necessarily need a refined subunit composition to exert its actions, a $\beta$ subunit is sufficient (Puia et al., 1990;
Rupprecht and Holsboer, 1999). Thus, a more fascinating novel research area could be to identify what neuronal networks ultimately are targeted by either $3 \alpha$-reduced neurosteroids or benzodiazepines. Do such neurosteroids and benzodiazepines recruit a different composition of postand extrasynaptic $\mathrm{GABA}_{\mathrm{A}}$ receptors? For example, future studies employing voltage sensitive dye imaging might address such questions. To what extent receptors other than $\mathrm{GABA}_{\mathrm{A}}$ receptors are involved in neurosteroid action?

As a more systemical approach neuroimaging studies in humans, e.g., by means of functional magnetic resonance tomography (fMRI), might compare the brain areas involved after administration of benzodiazepines (Leicht et al., 2013) with neurosteroids such as allopregnanolone. As such, a major issue of future research in this area should be the elucidation of the mechanisms of action of neurosteroids both at the molecular, cellular and brain network level.

Another important area of research is the role of neurosteroids such as allopregnanolone for normal and pathological behavior in animals and humans and for neuropsychiatric disorders. It is evident from many preclinical studies that neurosteroids modulate anxietyrelated behavior but nevertheless many issues are far from being understood. For example, what is the role of various neurosteroids with a different receptor profile acting in concert, e.g., pregnenolone and allopregnanolone? What about concentration and time dependency of neurosteroid effects? It may well be that such phenomena affect both physiological and pathological conditions. For example, it has been shown that negative mood symptoms may occur in women with premenstrual dysphoric disorder (PMDD) during the luteal phase of the menstrual cycle when progesterone and allopregnanolone levels usually are high (Bäckström et al., 2014) which has to be reconciled with the known anxiolytic effects of moderate to high concentrations of allopregnanolone. Moreover, in such patients there is an apparent discordance between the sensitivity to diazepam and allopregnanolone with decreased sensitivity to diazepam, whereas sensitivity to allopregnanolone is increased (Bäckström et al., 2014). A widely neglected research area is the role of isomers which acts as functional antagonists of allopreganolone, for example its $3 \beta$ epimer ( $3 \beta, 5 \alpha$-pregnanolone). All these compounds finally act in concert in the modulation of rodent and human behavior. An example for such an altered equilibrium of steroid composition is the prominent decline in $3 \alpha$-reduced neurosteroids after challenge with sodium lactate or cholecystokinin tetrapeptide (CCK-4) in patients with panic disorder together with a marked increase in the $3 \beta$-reduced isomer (Ströhle et al., 2003), which may result in a decreased GABAergic tone related to pathophysiology of panic attacks. Moreover, studies investigating the composition of neurosteroid profiles in neuropsychiatric disorders during differential psychopathological states are rare and need further elaboration. It is not surprising that neurosteroids such as allopregnanolone play a role in 
the pathophysiology of mood disorders (Schüle et al., 2014) and particularly for women (Schiller et al., 2014).

Besides their neuromodulatory potential a major issue is whether endogenous neurosteroids or synthetic neurosteroid derivatives can be used as novel therapeutic agents for the treatment of neuropsychiatric disorders. Ganaxolone is a first example of a synthetic $3 \alpha$-reduced neurosteroid which is under investigation for the treatment of epilepsy, e.g., infantile spams (Riikonen, 2014). Another attractive area of research is the use of neurosteroidogenic compounds to promote endogenous neurosteroidogenesis. Observations came from both preclinical and clinical studies that for example antidepressants such as selective serotonin reuptake inhibitors (SSRIs) or mirtazapine (Pinna et al., 2006; Schüle et al., 2014) may enhance neurosteroidogenesis probably through interference with neurosteroidogenic enzymes. Moreover, ligands of the translocator protein $18 \mathrm{kDa}$ (TSPO) have recently gained considerable attention as putative novel therapeutic agents in neuropsychopharmacology (Rupprecht et al., 2010). Numerous reports suggest that they promote the transport of cholesterol to the mitochondrial matrix thereby initiating neurosteroidogenesis, although recently the requirement of TSPO for steroidogenesis has been questioned (Morohaku et al., 2014; Tu et al., 2014). TSPO ligands are used as molecular imaging tools for assessing brain damage and microglia activation in positron emission tomography (PET) studies and have been suggested to exert potential beneficial effects in numerous preclinical investigations, for example peripheral nerve lesions (Rupprecht et al., 2010), neuropathic pain (Patte-Mensah et al., 2014), Alzheimer's disease (Chua et al., 2014), and retinal damage (Karlstetter et al., 2014). First clinical studies suggest that TSPO ligands, e.g., olesoxime, represent a therapeutic option in amyotrophic lateral sclerosis (Rupprecht et al., 2010). Moreover, TPSO ligands such as XBD173 or etifoxine may act as anxiolytic agents in clinical studies with a more favorable side effect profile than that of benzodiazepines (Rupprecht et al., 2009, 2010). It is intriguing that etifoxine is available in France since many years for the treatment of adjustment anxiety disorder. This shows that it is feasible to develop TSPO ligands for clinical indications with a favorable side effect profile.

In conclusion, neurosteroids, e.g., allopregnanolone, and neurosteroidogenic compounds such as TSPO ligands still represent a challenging area of research that has the potential to further elucidate the physiology of rodent and human behavior, the pathophysiology of neuropsychiatric diseases and to open the door for novel treatment avenues in neuropsychopharmacology.

\section{REFERENCES}

Bäckström, T., Bixo, M., Johansson, M., Nyberg, S., Ossewaarde, L., Ragagnin, G., et al. (2014). Allopregnanolone and mood disorders. Prog. Neurobiol. 113, 88-94. doi: 10.1016/j.pneurobio.2013.07.005

Chen, Z. W., Manion, B., Townsend, R. R., Reichert, D. E., Covey, D. F., Steinbach, J. H., et al. (2012). Neurosteroid analog photolabeling of a site in the third transmembrane domain of the $\beta 3$ subunit of the GABA(A) receptor. Mol. Pharmacol. 82, 408-419. doi: 10.1124/mol.112.078410

Chua, S. W., Kassiou, M., and Ittner, L. M. (2014). The translocator protein as a drug target in Alzheimer's disease. Expert Rev. Neurother. 14, 439-448. doi: 10.1586/14737175.2014.896201

Karlstetter, M., Nothdurfter, C., Aslanidis, A., Moeller, K., Horn, F., Scholz, R., et al. (2014). Translocator protein $(18 \mathrm{kDa})$ (TSPO) is expressed on reactive retinal microglia and modulates microglial inflammation and phagocytosis. J. Neuroinflammation 11:3. doi: 10.1186/1742-2094-11-3

Leicht, G., Mulert, C., Eser, D., Saemann, P. G., Ertl, M., Laenger, A., et al. (2013). Benzodiazepines counteract rostral anteriror cingulate cortex activation induced by CCK-4 in humans. Biol. Psychiatry 73, 337-344. doi: 10.1016/j.biopsych.2012.09.004

Morohaku, K., Pelton, S. H., Daugherty, D. J., Butler, W. R., Deng, W., and Selvaraj, V. (2014). Translocator protein/peripheral benzodiazepine receptor is not required for steroid hormone biosynthesis. Endocrinology 155, 89-97. doi: 10.1210/en.2013-1556

Patte-Mensah, C., Meyer, L., Taleb, O., and MensahNyagan, A. G. (2014). Potential role of allopregnanolone for a safe and effective therapy of neuropathic pain. Prog. Neurobiol. 113, 70-78. doi: 10.1016/j.pneurobio.2013.07.004

Pinna, G., Costa, E., and Giodotti, A. (2006). Fluoxetine and norfluoxetine stereospecifically and selectively increase brain neurosteroid content at doses that are inactive on 5-HT reuptake. Psychopharmacology 186, 362-372. doi: 10.1007/s00213-005-0213-2

Puia, G., Santi, M. R., Vicini, S., Pritchett, D. B., Purdy, R. H., Paul, S. M., et al. (1990). Neurosteroids act on recombinant human $\mathrm{GABA}_{\mathrm{A}}$ receptors. Neuron 4, 759-765. doi: 10.1016/0896-6273(90)90202-Q
Riikonen, R. (2014). Recent advances in the pharmacotherapy of infantile spasms. CNS Drugs 28, 279-290. doi: 10.1007/s40263-014-0139-5

Rupprecht, R., and Holsboer, F. (1999). Neuroactive steroids: mechanisms of action and neuropsychopharmacological perspectives. Trends Neurosci. 22 , 410-416. doi: 10.1016/S0166-2236(99) 01399-5

Rupprecht, R., Papadopoulos, V., Rammes, G., Baghai, T. C., Fan, J., Akula, N., et al. (2010). Translocator protein $(18 \mathrm{kDa})$ as a therapeutic target for neurological and psychiatric disorders. Nat. Rev. Drug Discov. 9, 971-988. doi: $10.1038 / \mathrm{nrd} 3295$

Rupprecht, R., Rammes, G., Eser, D., Baghai, T. C., Schüle, C., Nothdurfter, C., et al. (2009). Translocator Protein $(18 \mathrm{kDa})$ as target for anxiolytics without benzodiazepinelike side effects. Science 325, 490-493. doi: 10.1126/science. 1175055

Schiller, C. E., Schmidt, P. D., and Rubinow, D. R. (2014). Allopregnanolone as a mediatiator of affective switching in reproductive mood disorders. Psychopharmacology 231, 3557-3567. doi: 10.1007/s00213-014-3599-x

Schüle, C., Nothdurfter, C., and Rupprecht, R. (2014). The role of allopregnanolone in depression and anxiety. Prog. Neurobiol. 113, 79-87. doi: 10.1016/j.pneurobio.2013.09.003

Selye, H. (1941). Anaesthetic effects of steroid hormones. Proc. Soc. Exp. Biol. 46, 116-121. doi: 10.3181/00379727-46-11907

Ströhle, A., Romeo, E., di Michele, F., Pasini, A., Hermann, B., Gajewski, G., et al. (2003). Induced panic attacks shift $\mathrm{GABA}_{\mathrm{A}}$ receptor modulatory steroid composition in patients with panic disorder: preliminary results. Arch. Gen. Psychiatry 60, 161-168. doi: 10.1001/archpsyc.60.2.161

Tu, L. N., Morohaku, K., Manna, P. R., Pelton, S. H., Butler, W. R., Stocco, D. M., et al. (2014). Peripheral benzodiazepine receptor/transloctaor protein global knockkout mice are viable with no effects on steroid hormone biosynthesis. J. Biol. Chem. doi: 10.1074/jbc.M114. 578286. [Epub ahead of print].

Conflict of Interest Statement: The author declares that the research was conducted in the absence of any commercial or financial relationships that could be construed as a potential conflict of interest.

Received: 30 July 2014; accepted: 19 August 2014; published online: 19 September 2014.

Citation: Rupprecht $R$ (2014) New perspectives in neurosteroid action: open questions for future research. Front. Cell. Neurosci. 8:268. doi: 10.3389/fncel. 2014.00268

This article was submitted to the journal Frontiers in Cellular Neuroscience.

Copyright (c) 2014 Rupprecht. This is an open-access article distributed under the terms of the Creative Commons Attribution License (CC BY). The use, distribution or reproduction in other forums is permitted, provided the original author(s) or licensor are credited and that the original publication in this journal is cited, in accordance with accepted academic practice. No use, distribution or reproduction is permitted which does not comply with these terms. 